Article

\title{
Soft-Switching Bidirectional Three-Level DC-DC Converter with Simple Auxiliary Circuit
}

\author{
Woo-Young Choi * and Min-Kwon Yang \\ Division of Electronic Engineering, Chonbuk National University, Jeonju 561-756, Korea \\ * Correspondence: wychoi@jbnu.ac.kr; Tel.: +82-063-270-4218
}

Received: 16 August 2019; Accepted: 2 September 2019; Published: 3 September 2019

\begin{abstract}
This paper suggests a soft-switching bidirectional three-level DC-DC converter with a simple auxiliary circuit. The proposed converter uses auxiliary $L C$ resonant circuits so that the power switches operate under a soft-switching condition. The resonant operation of the $L C$ circuits makes power switches turn on at zero voltage, eliminating the turn-on switching power losses. The proposed converter improves the power efficiency, not using complex power switching circuits, but using simple $L C$ resonant circuits. The operation of the proposed converter is described according to its operation modes. Experimental results for a $1.0 \mathrm{~kW}$ prototype are discussed to verify its performance. The proposed converter achieved the power efficiencies of $97.7 \%$ in the step-up mode and $97.8 \%$ in the step-down mode, respectively, for the rated load condition.
\end{abstract}

Keywords: bidirectional three-level DC-DC converter; switching power loss; zero-voltage switching; power efficiency

\section{Introduction}

The non-isolated bidirectional three-level DC-DC converter has been widely used for energy storage systems [1-3]. As shown in Figure 1, it uses four series-connected power switches and two series-connected capacitors [1]. Switch voltage stresses are reduced by half as power switches are stressed on half of the full DC-link voltage [2]. It can use lower voltage-rated power switches, which have better switching performance than the power switches in the two-level converters [3]. Aside from energy storage systems [4], the bidirectional three-level DC-DC converter has been utilized for ultra-capacitor applications [5] and various electric vehicle charging applications [6,7]. However, it still has switching power losses as it operates under a hard switching condition [8]. Particularly, in the case of using metal oxide semiconductor field effect transistors (MOSFETs), the turn-on switching losses are highly increased as the converter operates at high frequency and high output load condition [9].

In order to reduce switching power losses, the converter should operate under a soft switching condition [8]. The quasi-resonant switching technique can be adopted for reducing switching power losses [10-13]. By varying the switching frequency, power switches operate in a quasi-sinusoidal way [10]. The converter operates at the boundary of continuous and discontinuous conduction modes [11]. The turn-on switching losses can be reduced by turning on the switch at its minimum voltage [12]. However, the inevitable drawback of the quasi-resonant switching technique is that the variable frequency control complicates the design of the filter circuits and control loops [13].

An alternative method to reduce switching power losses is to adopt the active clamp switching technique [14-16]. Auxiliary power switches are used for making power switches to operate under a soft-switching condition [14]. Power switches can be turned on at zero voltage with a constant switching frequency [15]. However, the active clamp switching scheme increases the voltage stress of the power switch, increasing the voltage rating of the power switch, which is not desirable for three-level switching power converters [16]. Moreover, the actively clamped converters using the 
auxiliary power switch require additional gate driving circuits, which cause additional gate driving power losses [17]. On the other hand, in [18] and [19], the three-level zero-voltage switching DC-DC converters have been suggested without using auxiliary power switch. Extra power diodes are required for power switches to be turned on at zero voltage. However, the converter in [18] operates only in the step-down mode, while the converter in [19] operates only in the step-up mode. Thus, the converters in [18] and [19] are not suitable for the bidirectional power conversion applications. More recently, the triangular current mode control method [20] has been applied to the bidirectional three-level DC-DC converter [21]. Although it does not require any auxiliary circuits, it suffers from conduction losses due to the extremely high circulating current, which limits its practical uses.

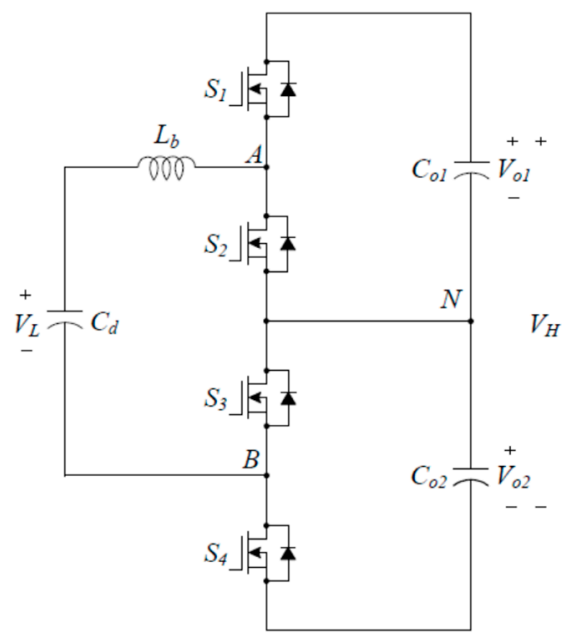

Figure 1. Circuit diagram of the conventional converter.

This paper aims to suggest a soft-switching bidirectional three-level DC-DC converter, which can effectively reduce the switching power losses with a simple auxiliary circuit. Figure 2 shows the circuit diagram of the proposed converter where two $L C$ resonant circuits are included. They allow zero-voltage switching of power switches, eliminating the turn-on switching power losses. The proposed converter operates under a soft-switching condition with a constant switching frequency. It does not use any auxiliary active or passive power semiconductor devices, which simplifies the converter design. The proposed converter reduces switching power losses and improves power efficiency, compared to the previous converters, which operate without any auxiliary circuits, suffering from high switching losses. Experimental results for a $1.0 \mathrm{~kW}$ prototype are discussed to verify its performance. The proposed converter achieved the power efficiencies of $97.7 \%$ in the step-up mode and $97.8 \%$ in the step-down mode, respectively, for the rated load condition. The key contributions of this paper are to introduce the proposed idea, to present its theoretical analysis, to evaluate its performance experimentally, and to discuss its utilization for industrial applications. 


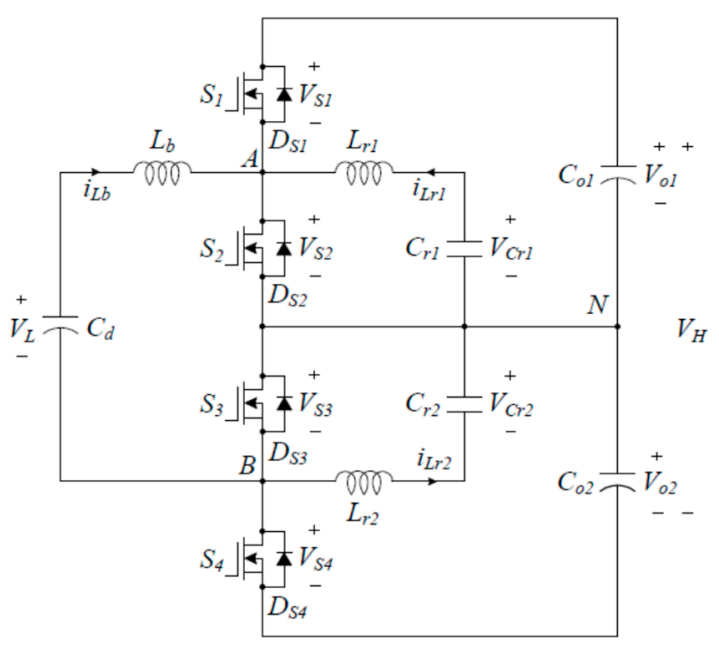

Figure 2. Circuit diagram of the proposed converter.

\section{Proposed Converter}

\subsection{Circuit Configuration}

Figure 2 shows the circuit diagram of the proposed converter. $V_{L}$ is the low voltage. $V_{H}$ is the high voltage. $C_{d}, L_{b}, S_{1}, S_{2}, S_{3}, S_{4}, C_{01}$, and $C_{02}$ consist of the bidirectional three-level DC-DC converter. Power switches $\left(S_{1} \sim S_{4}\right)$ include the body diodes $\left(D_{S 1} \sim D_{S 4}\right)$, respectively. Two identical $L C$ circuits $\left(L_{r 1}=L_{r 2}=L_{r}, C_{r 1}=C_{r 2}=C_{r}\right)$ are used for removing the turn-on switching losses of power switches. Power switches operate at a constant switching period $T_{s}$. The on-time of $S_{1}\left(S_{2}\right)$ is the same as the on-time of $S_{4}\left(S_{3}\right)$. The on-time of $S_{1}\left(S_{2}\right)$ is shifted by $T_{s} / 2$ with respect to the on-time of $S_{4}$ $\left(S_{3}\right) . S_{1}\left(S_{3}\right)$ and $S_{2}\left(S_{4}\right)$ operate complementary with a small dead time $T_{d}$. The inductor $L_{b}$ is large enough so that the inductor current $i_{L b}$ is continuous. The capacitors $C_{d}, C_{o 1}$, and $C_{o 2}$ are large enough so that the capacitor voltages $V_{L}, V_{o 1}$, and $V_{o 2}$ are constant. It is assumed that $V_{o 1}+V_{o 2}=V_{H}$ and $V_{o 1}=V_{o 2}=V_{H} / 2$. The resonant frequency $f_{r}$ of the $L C$ resonant circuit is assumed to be lower than the switching frequency $f_{S}$ of the converter. The capacitor voltages $V_{C r 1}$ and $V_{C r 2}$ are supposed to be constant during $T_{s}$.

\subsection{Control Operation}

The proposed converter operates in a step-up mode when the electric power is transferred from $V_{L}$ to $V_{H}$. As $S_{2}$ and $S_{3}$ are the main control switches, the duty cycle $D$ is defined as the ratio between the on-time $T_{o n}$ of $S_{2}\left(S_{3}\right)$ and $T_{s}$. The proposed converter operates in a step-down mode when the electric power is transferred from $V_{H}$ to $V_{L} . S_{1}$ and $S_{4}$ are the main control switches in the step-down mode. The duty cycle $D$ is defined as the ratio between the on-time of $S_{1}\left(S_{4}\right)$ and $T_{s}$. Only the operation principles of the converter in the step-up mode are addressed here because the operation principles of the converter in both modes are analogous. Figure 3 shows the circuit diagrams of the proposed converter according to the switches' states in the step-up mode. The proposed converter has four operation stages:

Stage I: The converter is in Stage I only when $D>0.5 . S_{2}$ and $S_{3}$ are turned on. $S_{1}$ and $S_{4}$ are turned off. $i_{L b}$ flows through $L_{b}, S_{2}, S_{3}$, and $C_{d}$. The following equation is obtained as

$$
-V_{L}+L_{b} \frac{d i_{L b}}{d t}=0
$$

$i_{L r 1}$ flows through $L_{r 1}, S_{2}$, and $C_{r 1}$. The resonance between $L_{r 1}$ and $C_{r 1}$ is expressed as

$$
-V_{C r 1}+L_{r 1} \frac{d i_{L r 1}}{d t}=0
$$




$$
C_{r 1} \frac{d V_{C r 1}}{d t}=i_{L r 1}
$$

$i_{L r 2}$ flows through $L_{r 2}, C_{r 2}$, and $S_{3}$. The resonance between $L_{r 2}$ and $C_{r 2}$ is expressed as

$$
\begin{gathered}
-V_{C r 2}+L_{r 2} \frac{d i_{L r 2}}{d t}=0, \\
C_{r 2} \frac{d V_{C r 2}}{d t}=i_{L r 2} .
\end{gathered}
$$

$S_{2}$ conducts $i_{L b}$ and $i_{L r 1}$, while $S_{3}$ conducts $i_{L b}$ and $i_{L r 2}$.

Stage II: The converter is in Stage II only when $D<0.5 . S_{2}$ and $S_{3}$ are turned off. $S_{1}$ and $S_{4}$ are turned on. $i_{L b}$ flows through $L_{b}, S_{1}, C_{o 1}, C_{o 2}, S_{4}$, and $C_{d}$. The following equation is obtained as

$$
V_{H}+L_{b} \frac{d i_{L b}}{d t}-V_{L}=0
$$

$i_{L r 1}$ flows through $L_{r 1}, S_{1}, C_{o 1}$, and $C_{r 1}$. The resonance between $L_{r 1}$ and $C_{r 1}$ is expressed as

$$
\begin{gathered}
-V_{C r 1}+L_{r 1} \frac{d i_{L r 1}}{d t}+V_{o 1}=0, \\
C_{r 1} \frac{d V_{C r 1}}{d t}=i_{L r 1} .
\end{gathered}
$$

$i_{L r 2}$ flows through $L_{r 2}, C_{r 2}, C_{o 2}$, and $S_{4}$. The resonance between $L_{r 2}$ and $C_{r 2}$ is expressed as

$$
\begin{gathered}
-V_{C r 2}+L_{r 2} \frac{d i_{L r 2}}{d t}+V_{o 2}=0, \\
C_{r 2} \frac{d V_{C r 2}}{d t}=i_{L r 2} .
\end{gathered}
$$

$S_{1}$ conducts $i_{L b}$ and $i_{L r 1}$, while $S_{4}$ conducts $i_{L b}$ and $i_{L r 2}$.

Stage III: $S_{2}$ and $S_{4}$ are turned on. $S_{1}$ and $S_{3}$ are turned off. $i_{L b}$ flows through $L_{b}, S_{2}, C_{02}, S_{4}$, and $C_{d}$. The following equation is obtained as

$$
V_{o 2}+L_{b} \frac{d i_{L b}}{d t}-V_{L}=0
$$

$i_{L r 1}$ flows through $L_{r 1}, S_{2}$, and $C_{r 1}$ in a similar way to Stage I. $i_{L r 2}$ flows through $L_{r 2}, C_{r 2}, C_{o 2}$, and $S_{4}$ in a similar way to Stage II. $S_{2}$ conducts $i_{L b}$ and $i_{L r 1}$, while $S_{4}$ conducts $i_{L b}$ and $i_{L r 2}$.

Stage IV: $S_{1}$ and $S_{3}$ are turned on. $S_{2}$ and $S_{4}$ are turned off. $i_{L b}$ flows through $L_{b}, S_{1}, C_{o 1}, S_{3}$, and $C_{d}$. The following equation is obtained as

$$
V_{o 1}+L_{b} \frac{d i_{L b}}{d t}-V_{L}=0
$$

$i_{L r 1}$ flows through $L_{r 1}, S_{1}, C_{o 1}$, and $C_{r 1}$ in a similar way to Stage II. $i_{L r 2}$ flows through $L_{r 2}, C_{r 2}$, and $S_{3}$ in a similar way to Stage I. $S_{1}$ conducts $i_{L b}$ and $i_{L r 1}$, while $S_{3}$ conducts $i_{L b}$ and $i_{L r 2}$. 


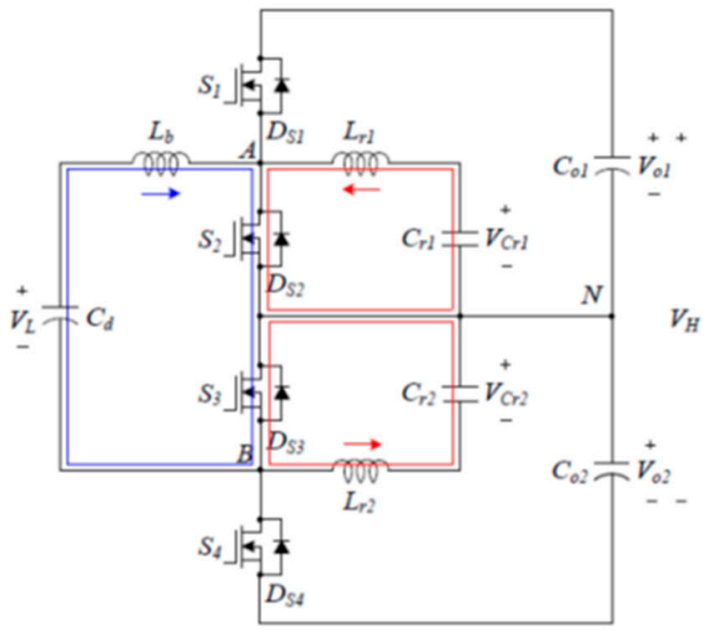

Stage I

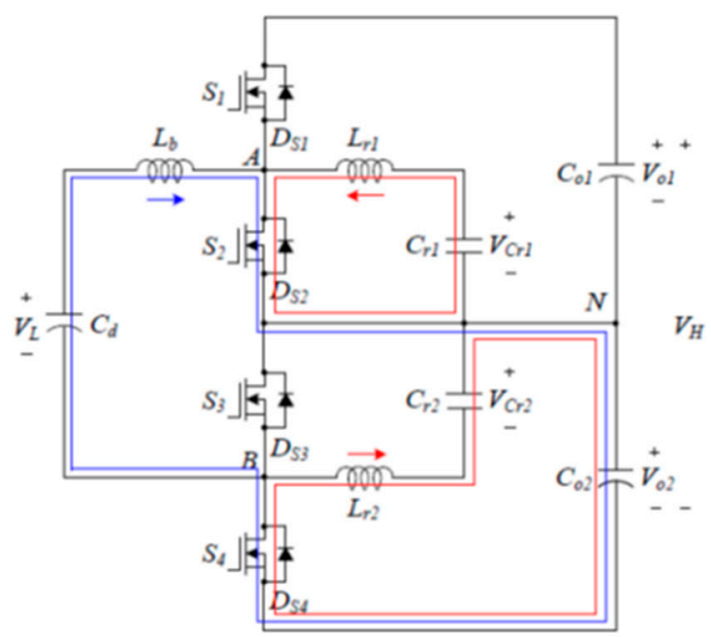

Stage III

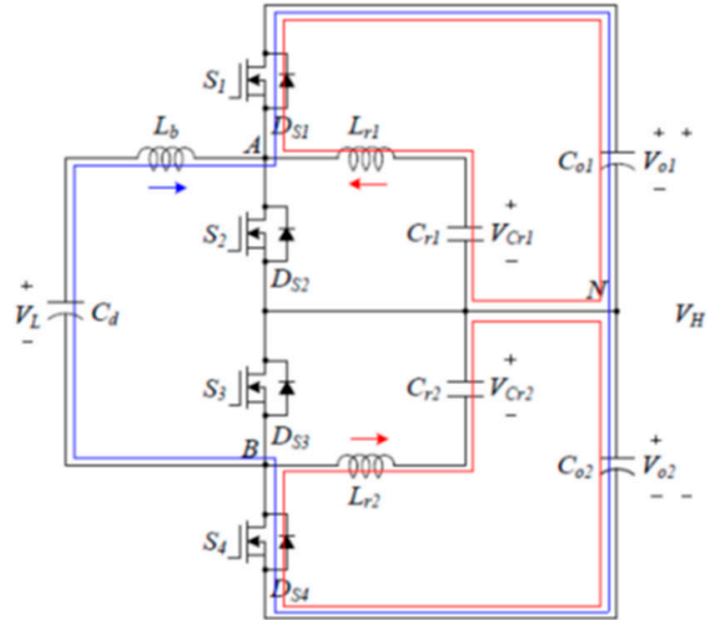

Stage II

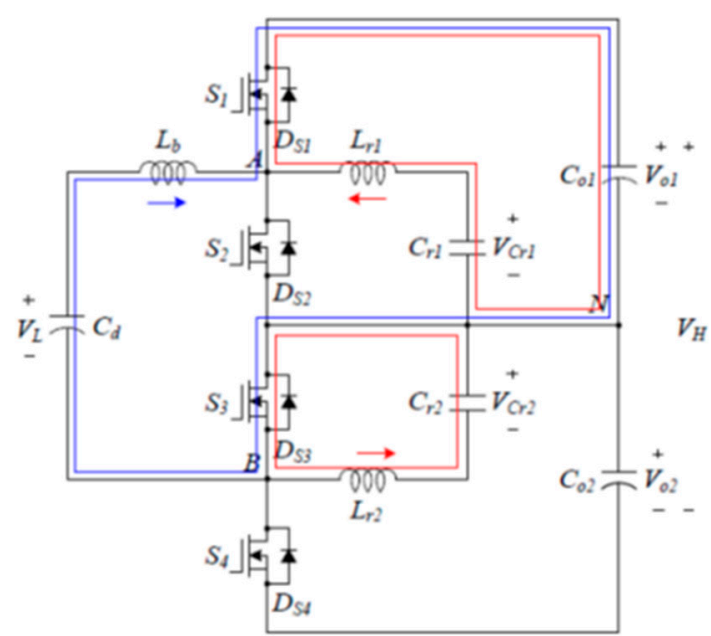

Stage IV

Figure 3. The circuit diagram of the proposed converter according to the switches' states in the step-up mode.

Figure 4 shows the operation waveforms of the converter in the step-up mode, for $D>0.5$ and $D<0.5$, respectively. $V_{g s 1}, V_{g s 2}, V_{g s 3}$, and $V_{g s 4}$ are the gate signals for $S_{1} \sim S_{4}$, respectively. $i_{S 1}, i_{S 2}, i_{S 3}$, and $i_{S 4}$ are the switch currents for $S_{1} \sim S_{4}$, respectively. 


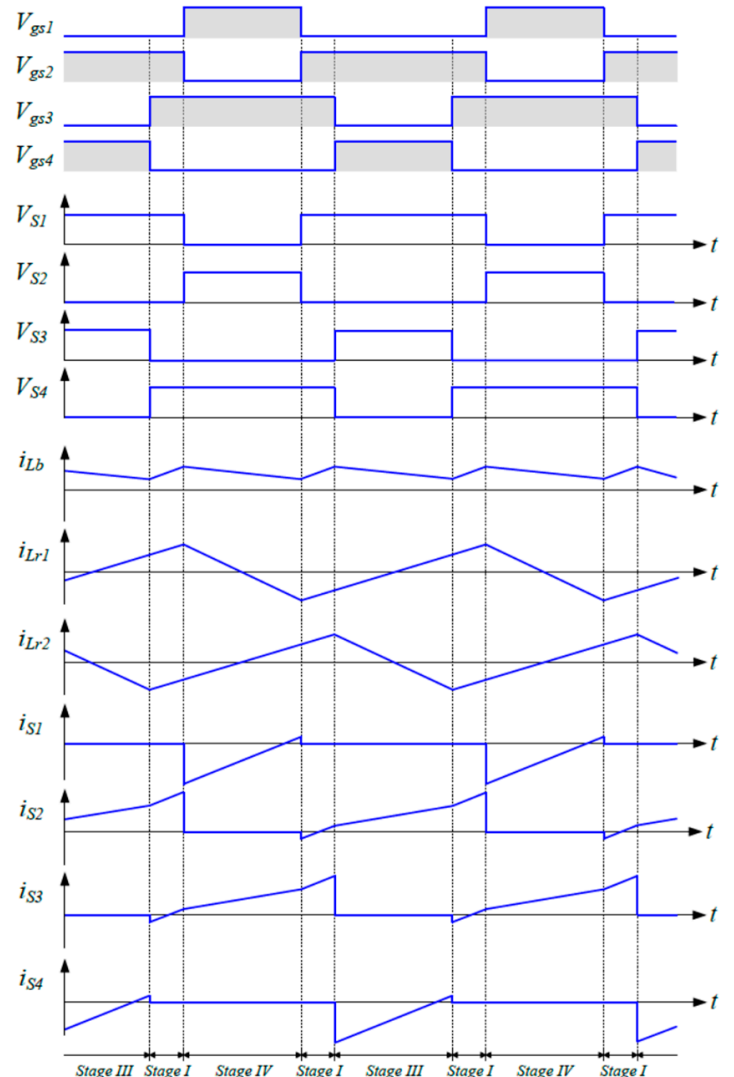

(a)

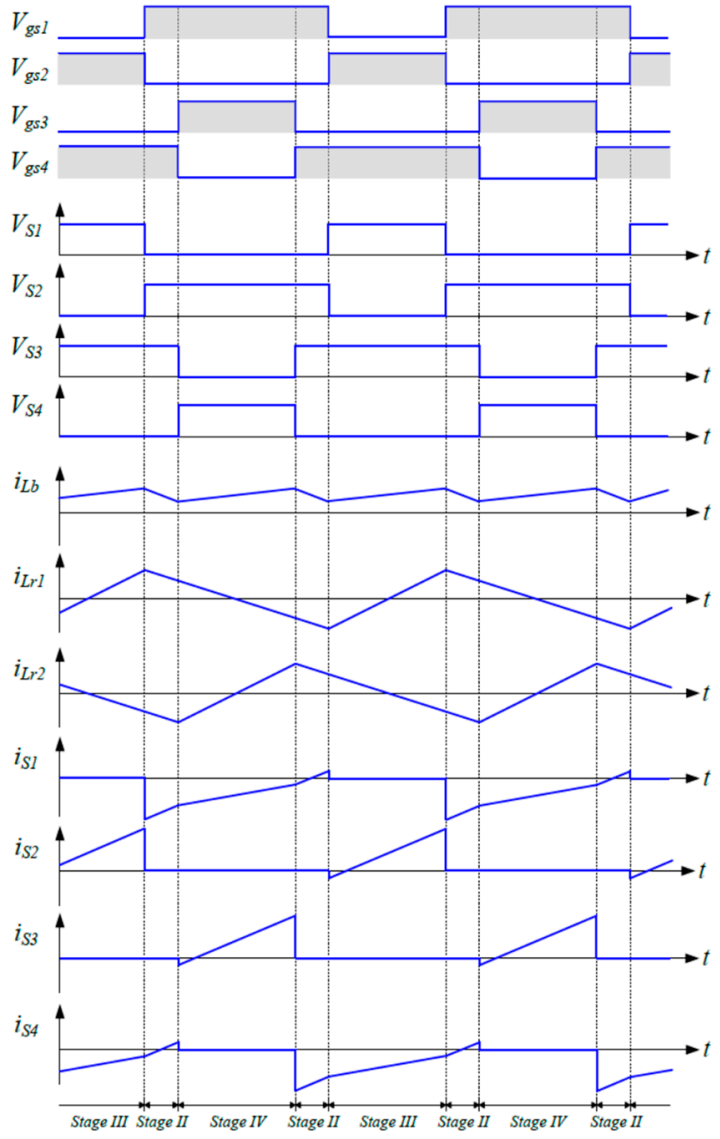

(b)

Figure 4. The operation waveforms when the converter operates in the step-up mode: (a) $D>0.5$; (b) $D<0.5$.

\subsection{Soft-Switching Condition}

Figure 5 shows the equivalent circuit diagrams of the proposed converter for the turn-on switching transition for $S_{1}$. This switching transition period corresponds to the switching time from Stage I to Stage IV in the step-up mode. $C_{S 1}$ and $C_{S 2}$ are the parasitic output capacitances of $S_{1}$ and $S_{2}$, respectively. As shown in Figure $5 \mathrm{a}, C_{S 1}$ has been charged to $V_{o 1}$ as $i_{L b}$ and $i_{L r 1}$ flow through $S_{2}$. Figure $5 \mathrm{~b}$ shows the circuit diagram for the switching transition moment when $S_{2}$ is turned off. $i_{L b}$ and $i_{L r 1}$ are split up between the capacitances, charging $C_{S 2}$ and discharging $C_{S 1}$. $C_{S 1}$ is completely discharged by $i_{L b}$ and $i_{L r 1}$, which flows in reverse through $S_{1}$. The switch voltage $V_{S 1}$ becomes zero before $S_{1}$ is turned on. $S_{1}$ can be turned on at zero voltage when a gating signal is applied to $S_{1}$, as shown in Figure 5 c. $C_{S 2}$ has been charged to $V_{o 1}$ as $i_{L b}$ and $i_{L r 1}$ flow through $S_{1}$. The switching transition for other power switches is analogous to the switching transition for $S_{1}$. 


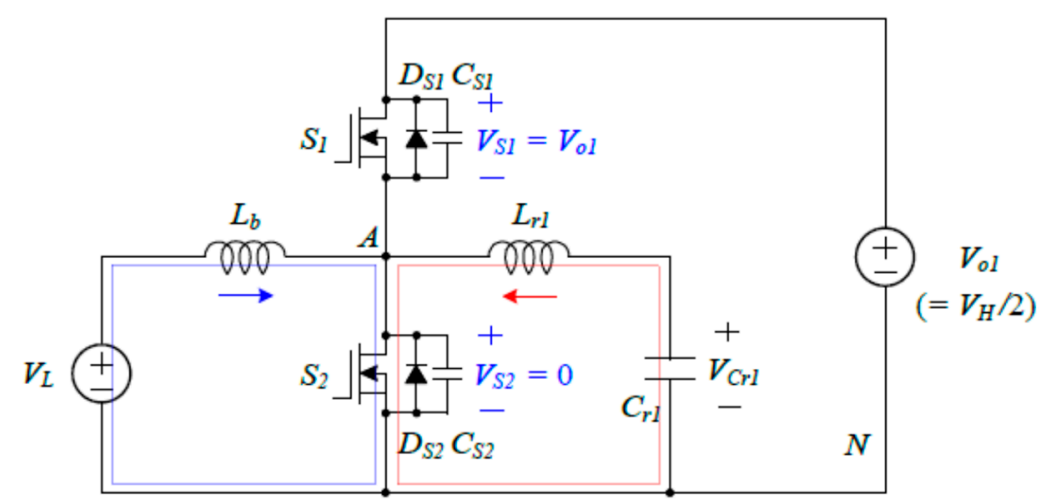

(a)

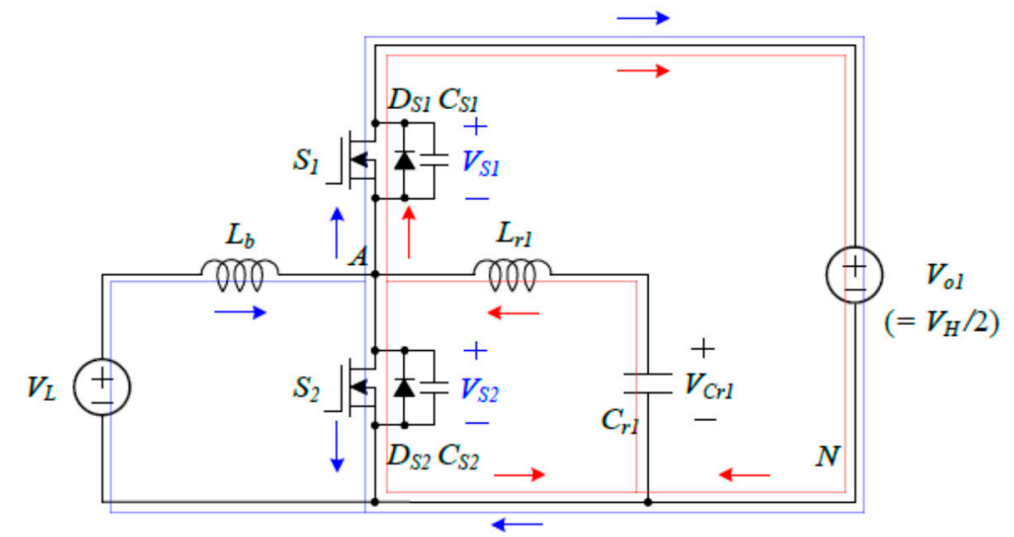

(b)

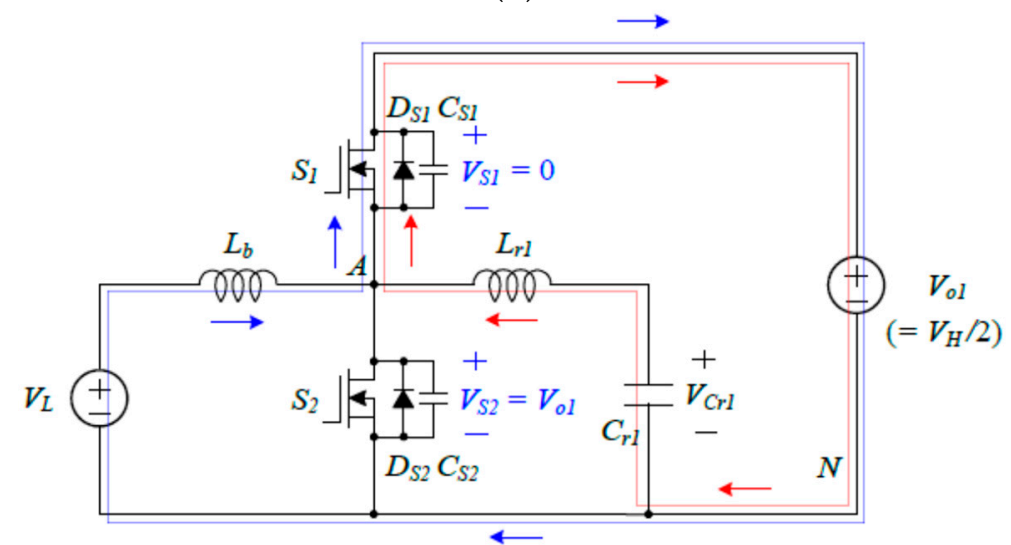

(c)

Figure 5. The equivalent circuit diagrams of the proposed converter for the turn-on switching transition for $S_{1}$ : (a) Stage I in the step-up mode; (b) switching transition from Stage I to Stage IV in the step-up mode; (c) Stage IV in the step-up mode.

The switch current $i_{S}$ becomes the sum of two inductor currents as $i_{L b}+i_{L r 1}$ for $S_{1}$ and $S_{2}$ and $i_{L b}+$ $i_{L r 2}$ for $S_{3}$ and $S_{4}$, respectively. In order to achieve the zero-voltage switching, $i_{S}$ should flow in reverse through the body diode of the switch at the switching transition moment. Then, $i_{S}$ should be lower than the zero current at the switching transition moment. For the moment from Stage I to Stage IV, the zero-voltage switching condition for $S_{1}$ can be expressed as

$$
\left|i_{L b, a v g}\right|+\frac{\Delta i_{L b}}{2}+\frac{\Delta i_{L r 1}}{2}>0
$$


where $\Delta i_{L b}$ and $\Delta i_{L r 1}$ are

$$
\begin{aligned}
\Delta i_{L b} & =\frac{V_{L}}{L_{b}} D T_{s}, \\
\Delta i_{L r 1} & =\frac{V_{L}}{L_{r 1}} D T_{s} .
\end{aligned}
$$

$\Delta i_{L b}$ is the current ripple of $L_{b}$, and $\Delta i_{L r 1}$ is the current ripple of $L_{r 1} \cdot\left|i_{L b, a v g}\right|$ is the absolute value of the average inductor current $i_{L b, a v g}$. By the assumption that $L_{r 1}=L_{r 2}=L_{r}$, the following relation can be obtained from Equation (13) as

$$
\frac{P_{d}}{V_{L}}+\frac{V_{L} T_{o n}}{2 L_{b}}+\frac{V_{L} T_{o n}}{2 L_{r}}>0
$$

where $P_{d}$ is the rated power of the proposed converter. For the moment from Stage IV to Stage $I$, the zero-voltage switching condition for $S_{2}$ can be expressed as

$$
\left|i_{L b, a v g}\right|-\frac{\Delta i_{L b}}{2}-\frac{\Delta i_{L r}}{2}<0
$$

which can be rewritten by Equations (14) and (15) as

$$
\frac{P_{d}}{V_{L}}-\frac{V_{L} T_{o n}}{2 L_{b}}-\frac{V_{L} T_{o n}}{2 L_{r}}<0 .
$$

Once $L_{r}$ is determined by Equation (18), Equation (16) can be satisfied without any constraint. By simplifying Equation (18), the inductance of $L_{r}$ can be chosen, which gives the design criterion of Lr as

$$
L_{r}<\frac{L_{b} V_{L}^{2} T_{o n}}{2 P_{d} L_{b}-V_{L}^{2} T_{o n}} .
$$

On the other hand, the switch current should operate under the above-resonant continuous mode to ensure the zero-voltage switching operation. Therefore, the switching frequency $f_{s}\left(=1 / T_{s}\right)$ of the converter should be higher than the resonant frequency $f_{r}$ of the $L C$ resonant circuit [22]. After the selection of $L_{r}$, the capacitance of $C_{r}$ can be determined by the following condition as

$$
f_{r}=\frac{1}{2 \pi \sqrt{L_{r} C_{r}}}<f_{s} .
$$

\section{Simulation and Experimental Results}

\subsection{Simulation Results}

Simulation results were obtained for the conventional converter in Figure 1 and the proposed converter in Figure 2. The simulations have been carried out by the physical security information management (PSIM) electronic simulation software. For the key system parameters of $V_{L}=150 \mathrm{~V}, V_{H}$ $=370 \mathrm{~V}, P_{d}=1000 \mathrm{~W}, T_{s}=50 \mu \mathrm{sec}, T_{d}=2 \mu \mathrm{sec}, L_{b}=600 \mu \mathrm{H}$, and $C_{o 1}=C_{o 2}=560 \mu \mathrm{F}$, Figure 6 shows the simulation results for the conventional converter. Figure 6 a shows the simulation results for the step-up mode, and Figure $6 \mathrm{~b}$ shows the simulation results for the step-down mode. As shown in Figure 6, a voltage spike is observed at the moment that each switch is turned off. This voltage spike causes the turn-on switching loss for the power switch, which eventually decreases the power efficiency. On the other hand, Figure 7 shows the simulation results of the proposed converter. The resonant parameters, such as $L_{r}=100 \mu \mathrm{H}$ and $C_{r}=2 \mu \mathrm{F}$, were used. Figure 7a shows the simulation results for the step-up mode, and Figure $7 \mathrm{~b}$ shows the simulation results for the step-down mode. Compared to the simulation results in Figure 6, no voltage spike is observed at the moment that each switch is turned off in the simulation results in Figure 7. With the help of the auxiliary circuit, the proposed converter eliminated the turn-on switching losses. 


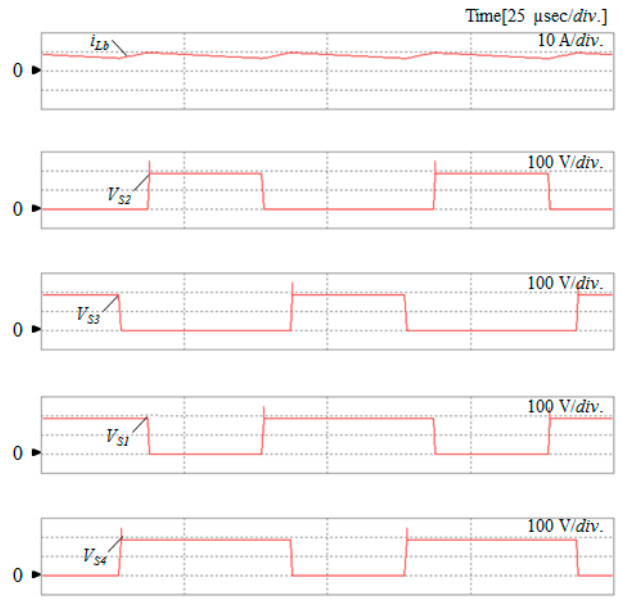

(a)

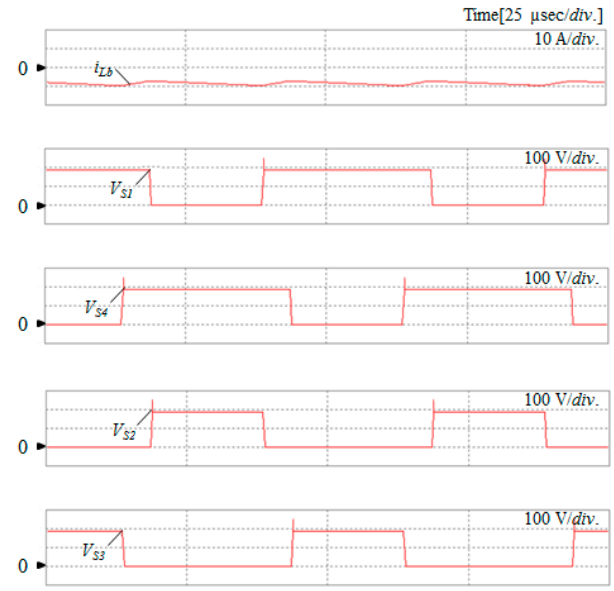

(b)

Figure 6. The simulation results of the conventional converter: (a) Step-up mode; (b) step-down mode.

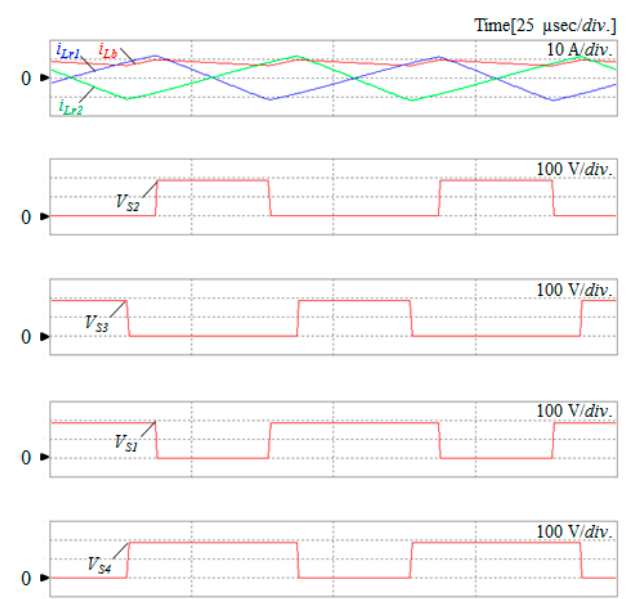

(a)

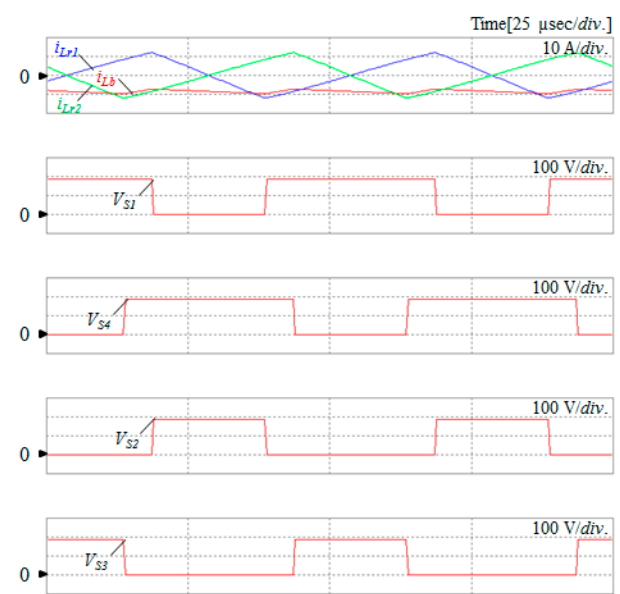

(b)

Figure 7. The simulation results of the proposed converter: (a) Step-up mode; (b) step-down mode.

\subsection{Experimental Results}

A $1.0 \mathrm{~kW}$ prototype circuit was designed and tested for the electrical specifications and circuit parameters in Table 1 . The low voltage $V_{L}$ ranges from $140 \mathrm{~V}$ to $160 \mathrm{~V}$. The high voltage $V_{H}$ ranges from $360 \mathrm{~V}$ to $400 \mathrm{~V}$. The valve-regulated lead-acid batteries were used for the low voltage side. Its nominal voltage for each battery cell is $24 \mathrm{~V}$. This type of system configuration can be utilized for grid-tied battery energy storage system applications where the battery power can be transferred into the grid or recharged from the grid.

Figure 8 shows the experimental waveforms of the conventional converter in Figure 1 in the step-up mode. The conventional converter can be tested by removing the $L C$ resonant circuits in the proposed converter. Figure 8 a shows $i_{L b}, V_{S 2}$, and $V_{S 3}$. Figure 8 b shows $i_{L b}, V_{S 1}$, and $V_{S 4} . i_{L b}$ is positively continuous because the converter is in the step-up mode. The on-time of $S_{1}\left(S_{2}\right)$ is shifted by $T_{S} / 2$, with respect to the on-time of $S_{4}\left(S_{3}\right)$. As shown in Figure 8 , a voltage spike is observed at the moment that each switch is turned off. This voltage spike causes the turn-on switching loss for the power switch, which eventually decreases the power efficiency. Figure 9 shows the experimental waveforms of the proposed converter in the step-up mode. Figure 9a shows $i_{L b}, i_{L r 2}, V_{S 2}$, and $V_{S 3}$. Figure $9 \mathrm{~b}$ shows $i_{L b}, i_{L r 1}, V_{S 1}$, and $V_{S 4}$. $i_{L b}$ is positively continuous. $i_{L r 1}$ and $i_{L r 2}$ flow bidirectionally with a phase-shift of $T_{S} / 2$ with respect to each other. At the moment that each switch is turned off, the voltage across the power switch is clamped to $V_{H} / 2$ as $185 \mathrm{~V}$. Figure $9 \mathrm{c}$ shows $V_{g s 2}, V_{S 2}, V_{g s 3}$, and $V_{S 3}$. 
Figure $9 \mathrm{~d}$ shows $V_{g s 1}, V_{S 1}, V_{g s 4}$, and $V_{S 4}$. As shown in Figure $9 \mathrm{c}$, d, the switch voltage decreases to zero voltage before the gate signal is applied to the power switch. Power switches are turned on at zero voltage. Figure 9 e shows $i_{S 2}, V_{S 2}, i_{S 3}$, and $V_{S 3}$. Figure 9 f shows $i_{S 1}, V_{S 1}, i_{S 4}$, and $V_{S 4}$. Compared to the experimental results in Figure 8, no voltage spike is observed at the moment that each switch is turned off in Figure 9. With the help of the auxiliary circuit, the proposed converter has eliminated the turn-on switching losses for $S_{1}, S_{2}, S_{3}$, and $S_{4}$ effectively in the step-up mode.

Table 1. Electrical specifications and circuit parameters.

\begin{tabular}{ccc}
\hline Symbol & Quantity & Value \\
\hline$V_{L}$ & low voltage & $140-160 \mathrm{~V}$ \\
$V_{H}$ & high voltage & $360-400 \mathrm{~V}$ \\
$P_{d}$ & rated power & $1000 \mathrm{~W}$ \\
$T_{S}$ & swiching period & $50 \mu \mathrm{sec}$ \\
$T_{d}$ & dead time & $2 \mu \mathrm{sec}$ \\
$S_{1}, S_{2}, S_{3}, S_{4}$ & power switch & IXFP30N25X3 \\
$C_{S 1}, C_{S 2}, C_{S 3}, C_{S 4}$ & capacitor & $1450 \mathrm{pF}$ \\
$L_{b}$ & inductor & $600 \mu \mathrm{H}(\mathrm{CM} 508125)$ \\
$C_{o 1}, C_{o 2}$ & capacitor & $560 \mu \mathrm{F} / 450 \mathrm{~V}$ \\
$L_{r 1}, L_{r 2}$ & inductor & $100 \mu \mathrm{H}(\mathrm{EE} 2828)$ \\
$C_{r 1}, C_{r 2}$ & capacitor & $2 \mu \mathrm{F} / 630 \mathrm{~V}$ \\
\hline
\end{tabular}

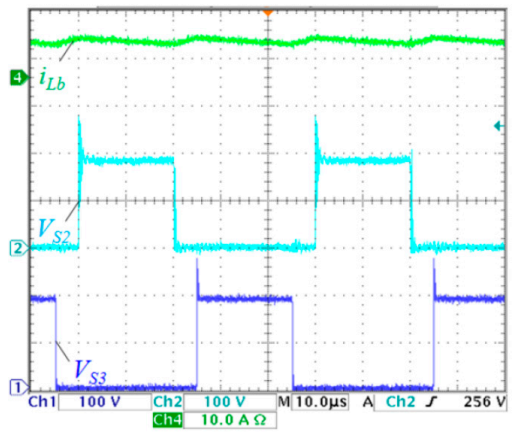

(a)

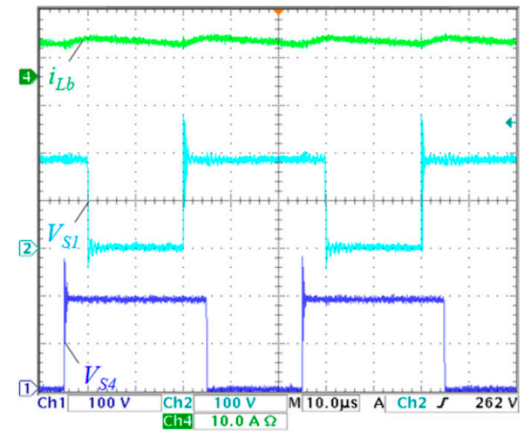

(b)

Figure 8. The experimental waveforms of the conventional converter in the step-up mode: (a) $i_{L b}, V_{S 2}$, and $V_{S 3} ;(\mathbf{b}) i_{L b}, V_{S 1}$, and $V_{S 4}$.

Figure 10 shows the experimental waveforms of the conventional converter in the step-down mode. Figure 10a shows $i_{L b}, V_{S 1}$, and $V_{S 4}$. Figure $10 \mathrm{~b}$ shows $i_{L b}, V_{S 2}$, and $V_{S 3}$. $i_{L b}$ is negatively continuous because the converter is in the step-down mode. The on-time of $S_{1}\left(S_{2}\right)$ is shifted by $T_{s} / 2$, with respect to the on-time of $S_{4}\left(S_{3}\right)$. As shown in Figure 10, a voltage spike is observed at the moment that each switch is turned off. This voltage spike causes the turn-on switching loss for the power switch, which eventually decreases the power efficiency. Figure 11 shows the experimental waveforms of the proposed converter in the step-down mode. Figure 11a shows $i_{L b}, i_{L r 1}, V_{S 1}$, and $V_{S 4}$. Figure $11 \mathrm{~b}$ shows $i_{L b}, i_{L r 2}, V_{S 2}$, and $V_{S 3} . i_{L b}$ is negatively continuous. $i_{L r 1}$ and $i_{L r 2}$ flow bidirectionally with a phase-shift of $T_{S} / 2$ with respect to each other. At the moment that each switch is turned off, the voltage across the power switch is clamped to $V_{H} / 2$ as $185 \mathrm{~V}$. Figure $11 \mathrm{c}$ shows $V_{g s 1}, V_{S 1}, V_{g s 4}$, and $V_{S 4}$. Figure $11 \mathrm{~d}$ shows $V_{g s 2}, V_{S 2}, V_{g s 3}$, and $V_{S 3}$. As shown in Figure $11 \mathrm{c}$, d, the switch voltage decreases to zero voltage before the gate signal is applied to the power switch. Power switches are turned on at zero voltage. Figure 11e shows $i_{S 1}, V_{S 1}, i_{S 4}$, and $V_{S 4}$. Figure $11 \mathrm{f}$ shows $i_{S 2}, V_{S 2}, i_{S 3}$, and $V_{S 3}$. Compared to the experimental results in Figure 10, no voltage spike is observed at the moment that each switch is turned off in Figure 11. By the operation of the auxiliary circuit, the proposed converter has eliminated the turn-on switching losses for $S_{1}, S_{2}, S_{3}$, and $S_{4}$ in the step-down mode. By eliminating the turn-on switching losses, the proposed converter increases the power efficiency for both step-up and step-down modes. 


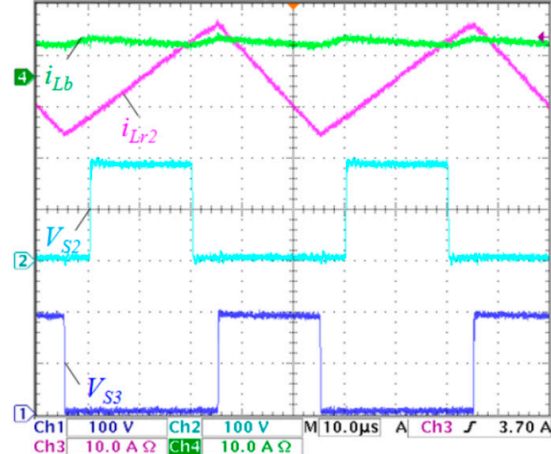

(a)

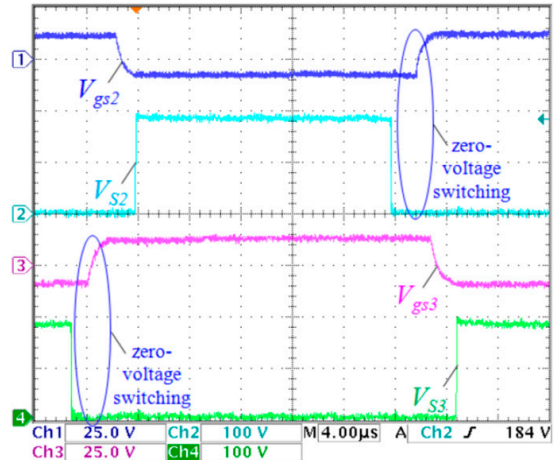

(c)

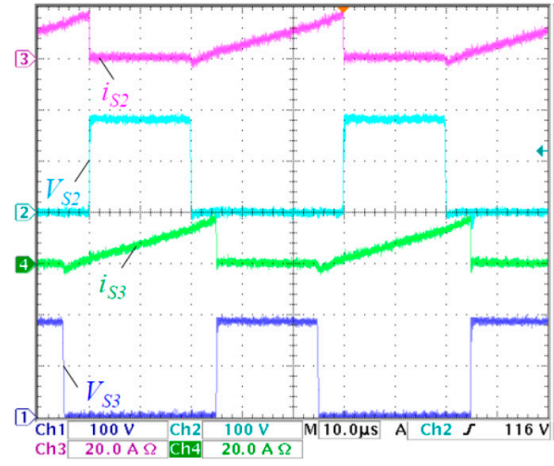

(e)

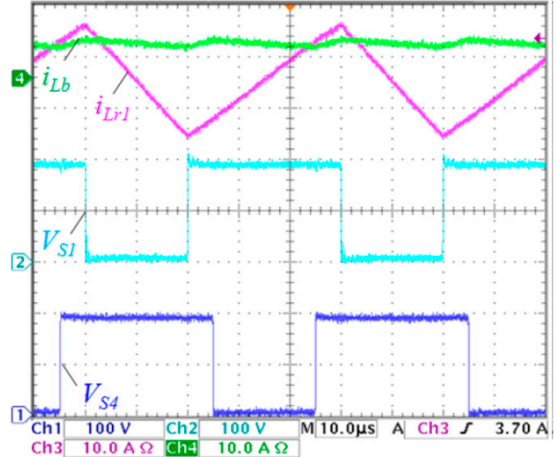

(b)

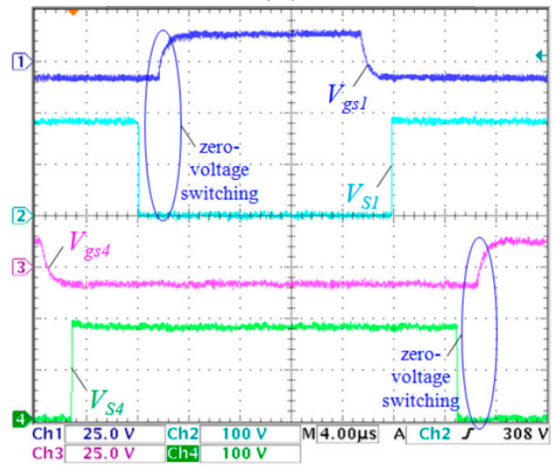

(d)

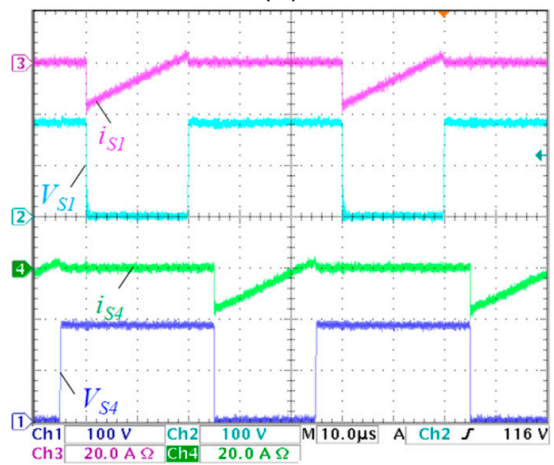

(f)

Figure 9. The experimental waveforms of the proposed converter in the step-up mode: (a) $i_{L b}, i_{L r 2}, V_{S 2}$, and $V_{S 3} ;$ (b) $i_{L b}, i_{L r 1}, V_{S 1}$, and $V_{S 4} ;$ (c) $V_{g s 2}, V_{S 2}, V_{g s 3}$, and $V_{S 3} ;(\mathbf{d}) V_{g s 1}, V_{S 1}, V_{g s 4}$, and $V_{S 4} ;(\mathbf{e}) i_{S 2}, V_{S 2}$, $i_{S 3}$, and $V_{S 3} ;(\mathbf{f}) i_{S 1}, V_{S 1}, i_{S 4}$, and $V_{S 4}$.

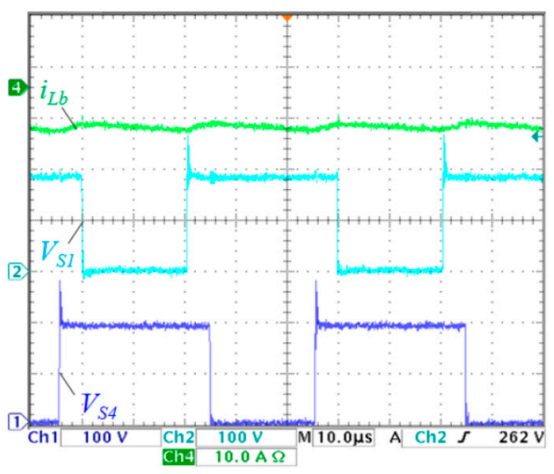

(a)

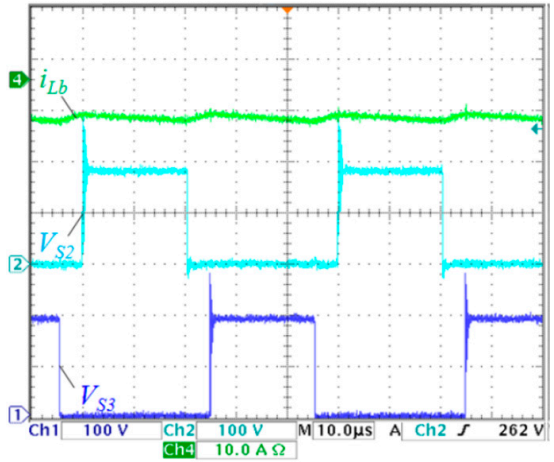

(b)

Figure 10. The experimental waveforms of the conventional converter in the step-down mode: (a) $i_{L b}$, $V_{S 1}$, and $V_{S 4} ;$ (b) $i_{L b}, V_{S 2}$, and $V_{S 3}$. 


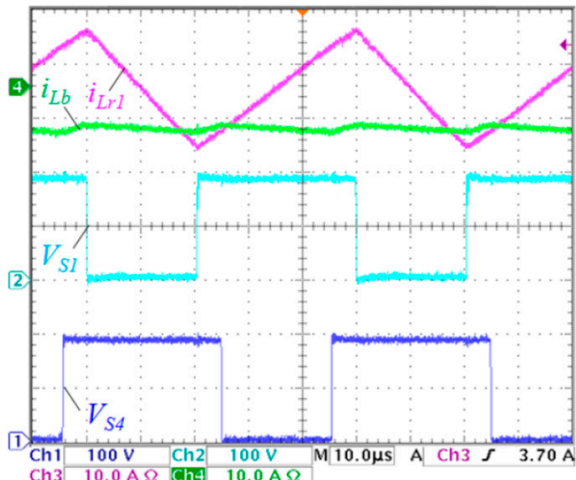

(a)

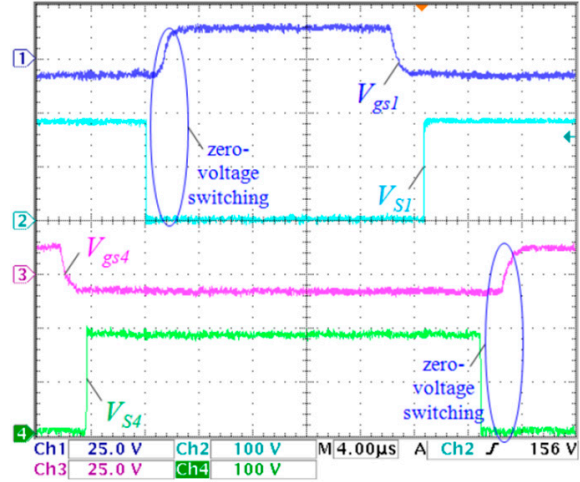

(c)

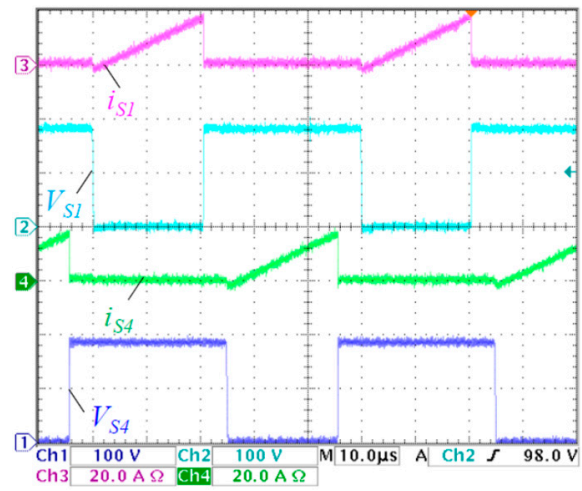

(e)

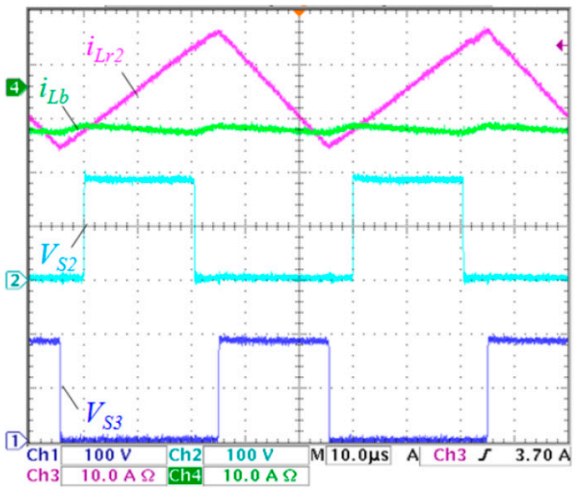

(b)

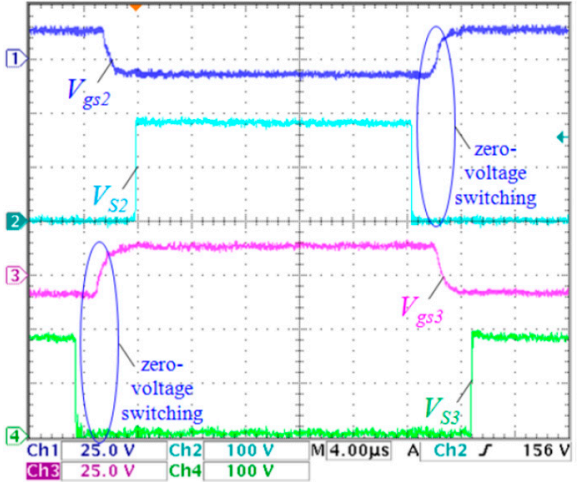

(d)

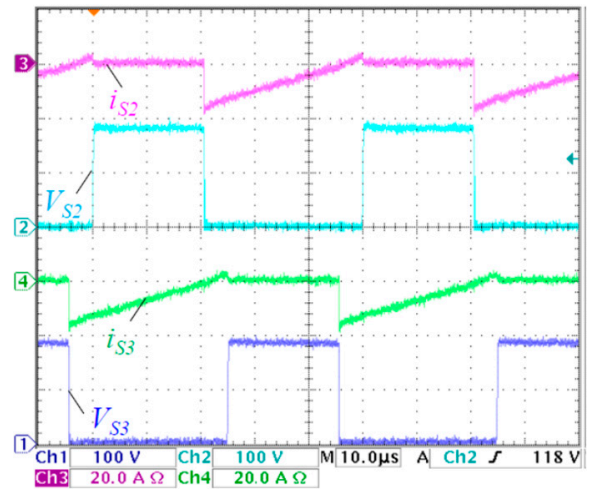

$(\mathbf{f})$

Figure 11. The experimental waveforms of the proposed converter in the step-down mode: (a) $i_{L b}, i_{L r 1}$, $V_{S 1}$, and $V_{S 4} ;(\mathbf{b}) i_{L b}, i_{L r 2}, V_{S 2}$, and $V_{S 3} ;$ (c) $V_{g s 1}, V_{S 1}, V_{g s 4}$, and $V_{S 4} ;$ (d) $V_{g s 2}, V_{S 2}, V_{g s 3}$, and $V_{S 3} ;(\mathbf{e}) i_{S 1}$, $V_{S 1}, i_{S 4}$, and $V_{S 4} ;(\mathbf{f}) i_{S 2}, V_{S 2}, i_{S 3}$, and $V_{S 3}$.

Figure 12 shows the power efficiency curves of the converters according to the operation modes. The power efficiency has been calculated by dividing the output power by the input power. The digital power meter (WT-230, YOKOGAWA) was used for the efficiency measurement. Figure 12a shows the power efficiency curves in the step-up mode. The conventional converter has an efficiency of $97.1 \%$ at $1.0 \mathrm{~kW}$. The peak efficiency is $97.6 \%$ at $0.7 \mathrm{~kW}$. The proposed converter has an efficiency of $97.7 \%$ at $1.0 \mathrm{~kW}$. The peak efficiency is $98.1 \%$ at $0.7 \mathrm{~kW}$. Figure $12 \mathrm{~b}$ shows the power efficiency curves in the step-down mode. The conventional converter has an efficiency of $97.2 \%$ at $1.0 \mathrm{~kW}$. The peak efficiency is $97.5 \%$ at $0.7 \mathrm{~kW}$. The proposed converter has an efficiency of $97.8 \%$ at $1.0 \mathrm{~kW}$. The peak efficiency is $98.2 \%$ at $0.7 \mathrm{~kW}$. Figure $12 \mathrm{c}$ shows the power efficiency curves of the proposed converter for different inductor values of $L_{r}$ at the rated power when $C_{r}$ is $2 \mu \mathrm{F}$. Figure $12 \mathrm{~d}$ shows the power efficiency curves of the proposed converter for different capacitor values of $C_{r}$ at the rated power when $L_{r}$ is $100 \mu \mathrm{H}$. 
As shown in Figure 12c, d, the proposed converter shows its best performance when $L_{r}=100 \mu \mathrm{H}$ and $C_{r}=2 \mu \mathrm{F}$ are chosen for the resonant parameters.

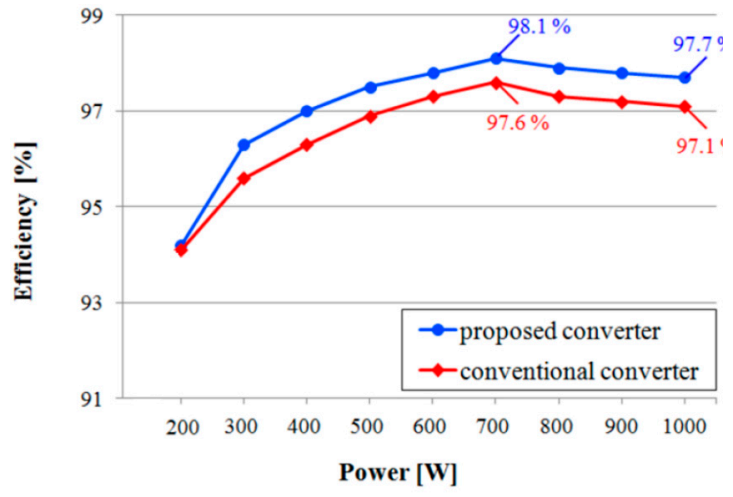

(a)

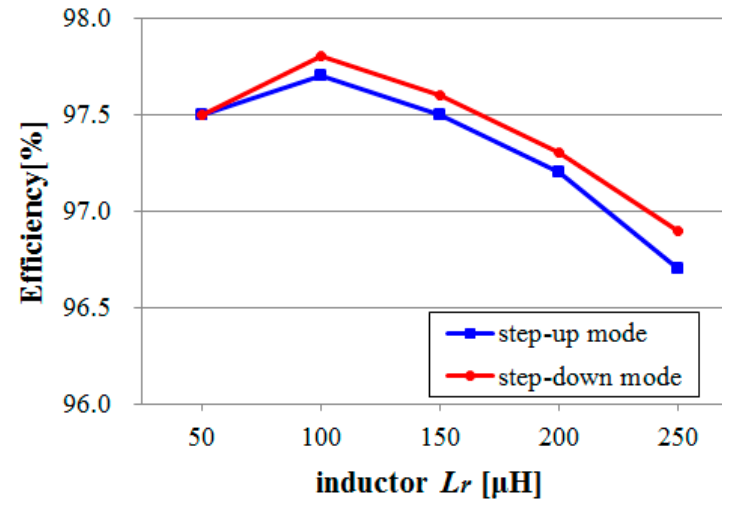

(c)

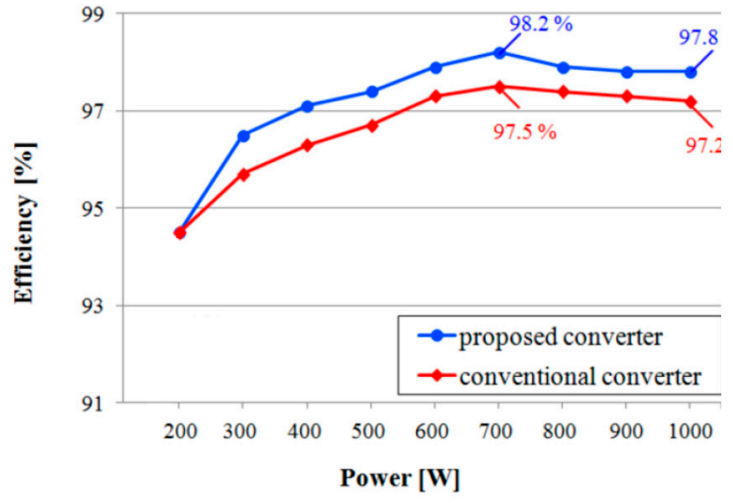

(b)

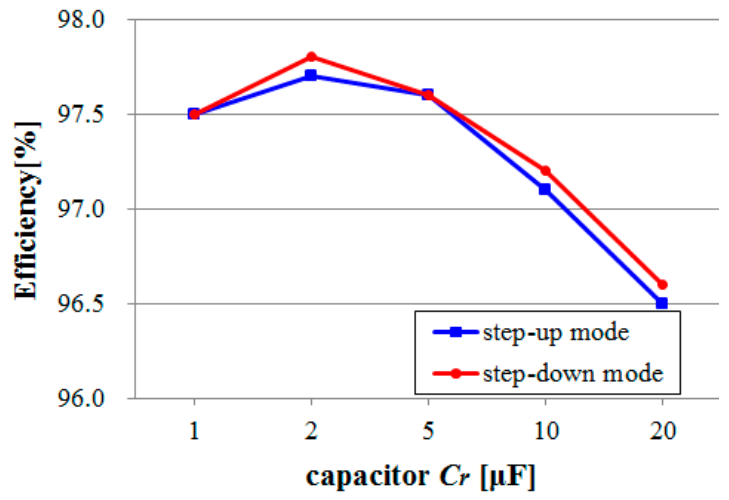

(d)

Figure 12. The power efficiency curves of the converters: (a) Power efficiency curves in the step-up mode; (b) Power efficiency curves in the step-down mode; (c) Power efficiency curves for different inductor values of $L_{r}$ at the rated power; (d) Power efficiency curves for different capacitor values of $C_{r}$ at the rated power.

\subsection{Power Loss Analysis}

The proposed converter improves the power efficiency by eliminating the turn-on switching loss $P_{\text {turn_on }}$ of the power switch, which is the most significant part of power losses when the MOSFETs are used. The proposed converter has turn-off switching losses and conduction losses. Assuming that $\Delta i_{L r}=\Delta i_{L r 1}=\Delta i_{L r 2}$, the average turn-off switching loss $P_{\text {turn_off }}$ is

$$
P_{\text {turn_off }}=\frac{V_{H}}{4 T_{S}}\left(\left|i_{L b, a v g}\right|+\frac{\Delta i_{L r}}{2}\right) t_{t u r n \_o f f}
$$

where $t_{\text {turn_off }}$ is the turn-off moment time, including the current falling time and the voltage rising time of the switch, as described in [23]. The average conduction loss $P_{\text {cond }}$ is

$$
P_{\text {cond }}=R_{d s(o n)} D\left(\left|i_{L b, a v g}\right|+\frac{\Delta i_{L r}}{2}\right)^{2}
$$

where $R_{d s(o n)}$ is the on-state resistance of the power switch. Other power losses $P_{\text {others }}$ for $L_{b}$ and switch gate-driving circuits are hardly affected by the proposed scheme, except the power losses for $L_{r 1}$ and $L_{r 2}$. The power loss $P_{\text {res } \_ \text {ind }}$ in the resonant inductor $L_{r}$ includes the copper loss and the core loss. Table 2 shows the power loss distributions of the converters for the step-up mode and the step-down mode. 
As the power level increases, the sum of $P_{\text {turn_on }}, P_{\text {turn_off }}$, and $P_{\text {cond }}$ in the conventional converter is higher than the sum of $P_{\text {turn_off }}, P_{\text {cond }}$, and $P_{\text {res_ind }}$ in the proposed converter.

Table 2. Power loss distributions of the converters.

\begin{tabular}{ccccc}
\hline & \multicolumn{2}{c}{ Step-Up Mode } & \multicolumn{2}{c}{ Step-Down Mode } \\
\cline { 2 - 5 } & $\begin{array}{c}\text { Conventional } \\
\text { Converter }\end{array}$ & $\begin{array}{c}\text { Proposed } \\
\text { Converter }\end{array}$ & $\begin{array}{c}\text { Conventional } \\
\text { Converter }\end{array}$ & $\begin{array}{c}\text { Proposed } \\
\text { Converter }\end{array}$ \\
\hline $\boldsymbol{P}_{\text {turn_on }}$ & $11.0 \mathrm{~W}$ & $0 \mathrm{~W}$ & $10.4 \mathrm{~W}$ & $0 \mathrm{~W}$ \\
$\boldsymbol{P}_{\text {turn_off }}$ & $7.6 \mathrm{~W}$ & $9.6 \mathrm{~W}$ & $7.4 \mathrm{~W}$ & $9.2 \mathrm{~W}$ \\
$\boldsymbol{P}_{\text {cond }}$ & $7.4 \mathrm{~W}$ & $9.0 \mathrm{~W}$ & $7.2 \mathrm{~W}$ & $8.6 \mathrm{~W}$ \\
$\boldsymbol{P}_{\text {res_ind }}$ & $0 \mathrm{~W}$ & $1.4 \mathrm{~W}$ & $0 \mathrm{~W}$ & $1.2 \mathrm{~W}$ \\
$\boldsymbol{P}_{\text {others }}$ & $3.0 \mathrm{~W}$ & $3.0 \mathrm{~W}$ & $3.0 \mathrm{~W}$ & $3.0 \mathrm{~W}$ \\
$\boldsymbol{P}_{\text {total }}$ & $29.0 \mathrm{~W}$ & $23.0 \mathrm{~W}$ & $28.0 \mathrm{~W}$ & $22.0 \mathrm{~W}$ \\
\hline
\end{tabular}

\section{Conclusions}

This paper has suggested a soft-switching bidirectional three-level DC-DC converter, which can effectively reduce the switching power losses with a simple auxiliary circuit. Two $L C$ resonant circuits were used for reducing the turn-on switching power losses of main power switches. Power switches are turned on at zero voltage by the resonant operation of the $L C$ resonant circuits. The proposed converter has reduced switching power losses and improves power efficiency, compared to the previous converters, which operate without any auxiliary circuits, suffering from high switching losses. The steady-state operation of the proposed converter was described. Its zero-voltage switching condition was analysed. A $1.0 \mathrm{~kW}$ prototype circuit was designed and tested for the experimental verifications of the proposed converter. The proposed converter achieved higher power efficiency than the conventional converter. It achieved the power efficiencies of $97.7 \%$ in the step-up mode and $97.8 \%$ in the step-down mode for the rated load condition.

The proposed converter can be utilized for a grid-tied battery energy storage system, which requires high power efficiency and high power density. Because of their three-level power conversion structure, high performance inverters, such as neutral point-clamped and three-level inverters, can be interfaced with the proposed converter. The proposed converter can be applied for the bidirectional DC-DC converter for both single-phase and three-phase grid-connected applications. The proposed converter is expected to be a good candidate for the interface between the battery and the grid-connected inverter to exchange electrical power with high efficiency and manage energy conversion.

Author Contributions: W.Y.C. managed the project, and mainly wrote the manuscript. M.K.Y. performed the experiments, analyzed the data, and edited the manuscript.

Funding: This research was supported by the National Research Foundation of Korea (NRF-2016R1D1A3B03932350).

Conflicts of Interest: The authors declare no potential conflict of interest.

\section{References}

1. Lin, C.C.; Yang, L.S.; Wu, G.W. Study of a non-isolated bidirectional DC-DC converter. IET Power Electron. 2013, 6, 30-37. [CrossRef]

2. Sulake, N.R.; Venkata, A.K.D.; Choppavarapu, S.B. FPGA implementation of a three-level boost converter-fed seven-level dc-link cascade H-bridge inverter for photovoltaic applications. Electronics 2018, 7, 282. [CrossRef]

3. Kim, J.Y.; Kim, H.S.; Beak, J.W.; Jeong, D.K. Analysis of effective three-level neutral point clamped converter system for the bipolar LVDC distribution. Electronics 2019, 8, 691. [CrossRef]

4. Han, S.H.; Kim, H.G.; Cha, H.; Chun, T.W. Bi-directional multi-level converter for an energy storage system. J. Power Electron. 2014, 14, 499-506. [CrossRef]

5. Mirzaei, A.; Farzanehfard, H.; Adib, E.; Jusoh, A.; Salam, Z. A fully soft switched two quadrant bidirectional soft switching converter for ultra-capacitor interface circuits. J. Power Electron. 2011, 11, 1-9. [CrossRef] 
6. Tan, L.; Wu, B.; Yaramasu, V.; Rivera, S.; Guo, X. Effective voltage balance control for bipolar-dc-bus-fed EV charging station with three-level dc-dc fast charger. IEEE Trans. Ind. Electron. 2016, 63, 4031-4041. [CrossRef]

7. Tan, L.; Zhu, N.; Wu, B. An integrated inductor for eliminating circulating current of parallel three-level dc-dc converter-based EV fast charger. IEEE Trans. Ind. Electron. 2016, 63, 1362-1371. [CrossRef]

8. Choi, W.Y.; Yang, M.K. High-efficiency design and control of Zeta inverter for single-phase grid-connected applications. Energies 2019, 12, 974. [CrossRef]

9. Lee, H.J.; Kim, Y.H. Analysis and design of a ZVT resonant boost converter using an auxiliary resonant circuit. Electronics 2019, 8, 466. [CrossRef]

10. Li, J.; Horck, F.B.M.; Daniel, B.J.; Bergveld, H.J. A high-switching-frequency flyback converter in resonant mode. IEEE Trans. Power Electron. 2017, 32, 8582-8592. [CrossRef]

11. Xie, X.; Li, J.; Peng, K.; Zhao, C.; Lu, Q. Study on the single-stage forward-flyback PFC converter with QR control. IEEE Trans. Power Electron. 2016, 31, 430-442. [CrossRef]

12. Li, Y.C. A novel control scheme of quasi-resonant valley-switching for high-power-factor ac-to-dc LED drivers. IEEE Trans. Ind. Electron. 2015, 62, 4787-4794. [CrossRef]

13. Park, J.P.; Moon, Y.J.; Jeong, M.G.; Kang, J.G.; Kim, S.H.; Gong, J.C.; Yoo, C.S. Quasi-resonant controller with adaptive switching frequency reduction scheme for flyback converter. IEEE Trans. Ind. Electron. 2016, 63, 3571-3581. [CrossRef]

14. Sergio, B.M.; Joan, N.A. A multilevel active-clamped converter topology - operating principle. IEEE Trans. Ind. Electron. 2011, 58, 3868-3878.

15. Choi, W.Y.; Yang, M.K.; Suh, Y.S. High-efficiency supercapacitor charger using an improved two-switch forward converter. J. Power Electron. 2014, 14, 1-10. [CrossRef]

16. Poorali, B.; Jazi, H.M.; Adib, E. Single-core soft-switching high step-up three-level boost converter with active clamp. IET Power Electron. 2016, 9, 2692-2699. [CrossRef]

17. Wang, J.; Li, R.T.; Chung, H.S. An investigation into the effects of the gate drive resistance on the losses of the MOSFET-snubber-diode configuration. IEEE Trans. Power Electron. 2012, 27, 2657-2672. [CrossRef]

18. Rodrigues, J.P.; Mussa, S.A.; Heldwein, M.L.; Perin, A.J. Three-level ZVS active clamping PWM for the DC-DC buck converter. IEEE Trans. Power Electron. 2009, 24, 2249-2258. [CrossRef]

19. Rodrigues, J.P.; Mussa, S.A.; Barbi, I.; Perin, A.J. Three-level zero-voltage switching pulse-width modulation DC-DC boost converter with active clamping. IET Power Electron. 2010, 3, 345-354. [CrossRef]

20. Wang, B.; Yuan, Y.; Zhou, Y.; Sun, X. Buck/boost bidirectional converter TCM control without zero-crossing detection. In Proceedings of the IEEE International Power Electronics and Motion Control Conference (IPEMC, 2016), Hefei, China, 22-26 May 2016.

21. Wang, Y.; Yang, J.; Zhang, B.; Jiang, X.; Kang, Z.; Ni, T.; Li, W. TCM controller design for three-level bidirectional soft-switching dc-dc converter. In Proceedings of the IEEE International Symposium on Industrial Electronics (ISIE, 2019), Vancouver, BC, Canada, 12-14 June 2019; pp. 996-1001.

22. Ang, S.; Oliva, A. Power Switching Converters; CRC Press: Boca Raton, FL, USA, 2011; pp. 1-488.

23. Mohan, N. Power Electronics: A First Course; John Wiley \& Sons: Hoboken, NJ, USA, 2012.

(C) 2019 by the authors. Licensee MDPI, Basel, Switzerland. This article is an open access article distributed under the terms and conditions of the Creative Commons Attribution (CC BY) license (http://creativecommons.org/licenses/by/4.0/). 